lying-in hospital of this capital, becense apposed not only to hinglish usages, but to all notions of dbeency ar propriety 3 Experience proves the negrative. Much less do I see reason to abste the delight I experience on reflecting that the lowest class of prostitutes, in some of the crowded that the lowest cinstial Europe, are being made the objects capitals of continental hurope, are being to preconceived opinions, do not appear to injure them, while they afford a prospect of benefit to the whole family of mankind.

Vienns, 127 Alserrorstadt, July 218t, 1854.

\section{SUCCESSFUL CASE OF EXCISION OF THE KNEE-JOINT.}

By CHARLES COTTON, M.D., F.R.C.S., Senior Surgeon to the West Norfolk and Lynn Hospital.

Thomas NeEPs, aged nine years, son of a peasant, was admitted into the West Norfolk Hospital on April 30th, 1853, with diseased right knee, of three years' standing. There was considerable chronic enlargement of the knee; the limb was semi-flexed; the foot was everted; the tibia was partially displaced backwards; and the patella was drawn upwards and onwards upon the external condyle. The patient had a sickly and worn aspect. He was of ordinary stature, had a sickly and to be spare. Full diet and cod-liver oil were ordered; and he was directed to remain in bed, and to have iodine paint moderately applied to the affected joint.

May 12th. No improvement. The knee was painful and uneasy. Chloroform having been inhaled, the limb was forcibly straightened by grasping the thigh with the left hand, and the leg with the right. This was effected with considerable difficulty (owing to firmly resisting adhesions), but without laceration of the integuments of the ham, which not unusually occurs in old cases of contracted knee. The limb was secured in the extended position upon a M'Intyre's splint; the joint ends of the bones still, however, retaining nearly the same malposition. Flannels, wrung out of hot water, were ordered to be constantly wrung and to be followed by belladonna lotion.

Na 13th. "No increased action or pain in the joint had occurred. He took an anodyne every night.

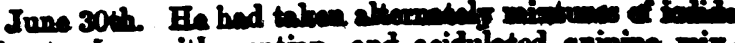

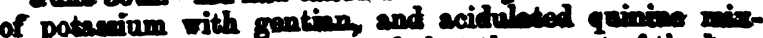
urea. His heelth was improved; but the eapect of the bue was the same, though it was mowe eng thas formedy, enabling him to sit up, and to be mored abont tha waids.

July 9th. The limb was adjusted an a M'Intype oplint. Made an out-patient, in order that ho might have the benefit of country air.

Aug. 15th. He presented himself, complaining of roturning pain and uneasiness in the kneo. The oplint wan re-adjusted. He was ordered to have cod-liver oil daily, and returned home with an understanding that, should he become worse, he was to re-enter the hospital.

Sept. 27th. Patient readmitted. General health much impaired; was pale and siclly. He had no appetite, got but. little sleep at night, and suffered much from pain in the knoe, which was tender to the touch. The foot, secured to the footpiece, was with the thigh and knee twisted outwards, the petient having turned the splint above to the inner side, giving the whole limb a very awkward appearance. On removing the splint, the integuments were found sound, and the knee much enlarged ; but there did not appear any material fulness from fluid in the joint. The patella was completely dislocated on the outer condyle; the tibia was displaced backwands and outwards; and the condyles of the femur projected forwards and inwards. The whole leg and foot were so greatly rotated outwards on the femur, that the inner ankle was placed directly forwards, whilst the external malleolus was inclined completely in an opposite direction. The least examination of the limb caused apparently agonising pain. The knee was shortly after condemned in consultation; and the choice of amputation or excision being left to the discretion of the surgeon, the latter was determined upon.

Oct. 5th. Operation. The boy, under the complete influence of chloroform, having been placed upon the operating table, the usual letter $\mathbf{H}$ incisions were boldly and quickly made. The flaps having been reflected, the patella being diseased, was at once removed, exposing the joint, and giving exit to a quantity of pus. The remaining fleshy and ligan mentous connexions were further divided by cutting close around the bones; and the partially destroyed crucial ligaments were also detached. The ends of the bones, which were carious and destitute of cartilage, being made to project by

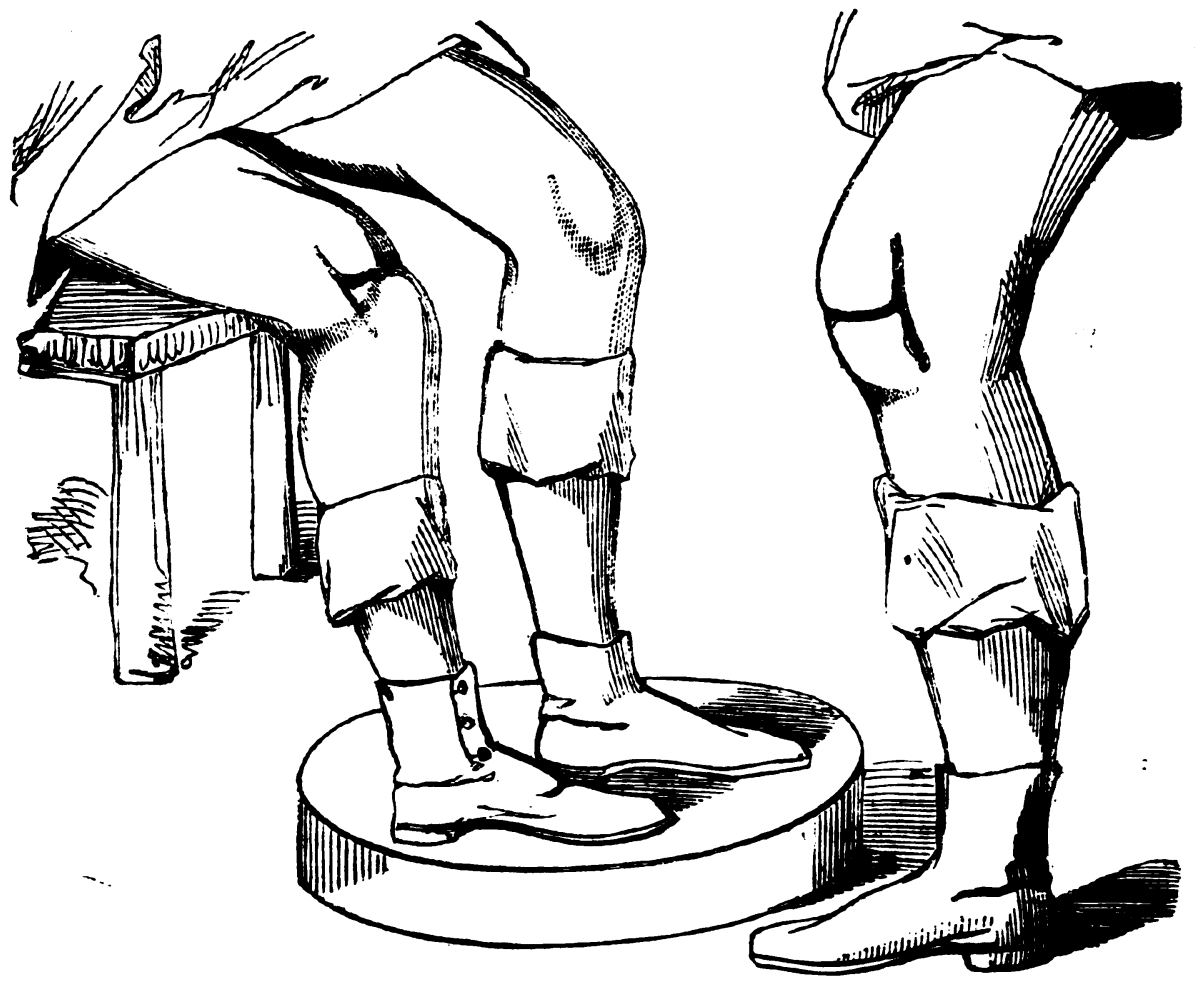


ering the fimb the or appled to the fomur, and a thin stice of its diseased surface was remored. The head of the tibis, which was much damaged, was treated in a cimilar manner; whilat that of the fibula, alsa involved, was excised with the cutting forceps. On bringing the parts into contact, by extending the limb, and correcting the eversion of the foot, the ends of the bones were found somewhat separated in front, but tightly wedged together posteriorly, the femur projecting considerably forwards. An additional slice of that bone was consequently cut with the saw, at a Verel angle, in a posterior direction; the soft parts and vessels being protected by a copper spatula ; and the projecting edge in front was further bevelled off previously to adjusting the limb upon a ready prepared M'Intyre's splint. One vessel at the bottom of the wound, the azygos articular, spouted at first freely, but no bleeding of importance occurred. The flaps were brought loosely together by six sutures; and the boy was conveyed at once to bed, where he commenced whining and crying, from smarting at the knee, on recovering from the effects of the chloroform.

Evening. He had taken a draught of sedative tincture of opium. He had had some sleep, and was free from pain. A rather free oozing of blood was restrained by the application of a solution of benzoin and alum.

Oct. 6th. Quiet and comfortable; had caten his food. Some vomiting occurred in the night, which was attributed to the chloroform. The anodyne draught repeated at night.

Oct. 7 th. He had had a good night, and enjoyed his egg at breakfast, and boiled mutton at dinner, but vomited once after the latter meal. The anodyne at night was omitted, and occasional effervescing draughts of citrate of potash were ordered. The sutures were removed, the tension of the bandage relieved, and water-dressing applied.

Oct. 8th. Passed an easy night. The limb was comfortable, and looked well.

Evening. The face a little flushed. He was somewhat fretful because the knee ached. The anodyne repeated.

Oct. 9th. He had had a good night, and said he was very well. The leg was easy; the wound suppurating. In the evening, there was a little feverishness and return of uneasiness in the knee. To have his anodyne.

Oct. 10th. No pain; the knee looking well.

Oct. 12th. The splint was readjusted, as he complained of the heel; and the bed was rendered more comfortable. The wound was discharging curdy cream-like pus. He was ordered to have wine, and any kind of food he preferred.

Oct. 16th. General health better, and appetite improved. The knee was puffy, soft, and spongy, though quite easy. The limb being somewhat displaced. Another splint was adapted, and the knee lightly bandaged. The patient was removed to a fresh bed, without complaint on his part.

Oct. 20th. The knee much improved in appearance; the discharge no longer curdy.

Oct. 27th. The edges of the incisions healing; the knce much less in size; and the discharge healthy.

Nov. 10th. The health greatly improved. The wound had considerably healed; the principal outlet was on the inner side of the knee, where the granulations were pale, flabby, and strumous looking. The limb was placed upon another splint.

Oct. 12th. He moved himself into another bed without sossistance.

Nov. 26th. The transverse incision just healed. Two small hollow discharging outlets remained, one on each side of the knee. The patient was hearty, and gaining flesh. He could move the limb, with the aid of the sound log, without inconvenience; and was desirous of getting up.

Dec. 26th. He sat up; an immaterial nlcerating surface alone remaining on the outer side of the joint. He was directed not to amuse himself so frequently with flexing the knee upon the splint, to which habit attention had been directed.

Feb. 1st, 1864. The splint had been dispensed with some days. He sat before the fire, with the knee bent; and elevated the limb with ease. A high heeled boot was supplied, to compensate for moderate shortening. He was ordered to be allowed to range the wards at will, as the constantly sitting posture seemed to cause a tendency to throw the end of the femur forwards.

March 9th. He had been detained in the hospital up to this period for security's sake. His health and condition were excellent, and the wound was healed soundly. Made an out-patient.

July 26th. Present condition of the patient. The boy has occasionally presented himself at the hospital up to this time. He attends regularly at the village school, a distance from home. He walks firmly, and with tolerable speed, though with a stooping gait, which he is trying to correct, and which he thinks is owing to his having been obliged to sit so long a time at the hospital. The tendency forwards of the femur is strikingly lessened. There exists considerable power of flexion at the knee. The limb is equally dereloped with its fellow, and he is able to project it forwards or backwards with ease. Indeed, up to this period, the case, without exception, has been deemed one of a highly satisfactory character.

Remanks. Formidable resections in the regions of continuity of bones, and forcible streightenings of the limbs, in all vicious positions of the knee, wo matter the stage of disease, as directed by M. Bonnet, hare for several years been neither novelties nor unsuccesstul proceedings in my practice at the Lynn Hospital, as the neighbouring professional gentlemen can testify, who have embraced the opportunity of witnessing the operations. Mly excisions of importance in the regions of joints have been, however, confined to four, one of the hip,* two of the elbow, $t$ and one of the knee. That of the hip-a desperate but extremely interesting case of a girl-led to several months of ease and comfort; and death, as shown at the post mortem inspection, was in no way induced by the operation. The two elbow excisions, in male and fenale adults, ultimately ended unfavourably, as I was obliged to amputate the upper arm in both cases, sereral months afterwards, at the request of the parties; in the one, for recurring disease of the elbow, and necrosis of the humerus; in the other, owing to the limb having become wasted and useless-in fact, an encumbrance. In the case of the knee (now abstracted from the rough notes of uny case-book, upwards of nine months after the operation), I was glad to embrace the opportunity of attempting the saving of the condemned limb by cutting out the knee-a proceeding I was about to put in practice so long ago as $1845, \pm$ in a case of scrofulous degeneration of the joint, but for the negative sanction of the physicians, and a deference to a surgical opinion in favour of amputation. The youth of the patient, and the anæsthetic value of chloroform, together with my experience, which justifies no extreme fear of interference when the larger joint ends of bones have become severely diseased, led me to give a trial to excision in the present instance; and, strengthened by the result, and the reported cases of Mr. Jones of Jersey, and also by the very elaborate paper of Mr. Mackenzie in the Monthly Jouviarl, I see no reason to regret my disregard of the strongly expressed and somewhat hastily promulgated censures of the Edinburgh authorities, for whose opinions in general I have the highest respect. I am no exclusive reportcr of wondrous cures; neither do I presume to lecture upon an individual case, for, by the aggregate of successes and reverses, operative surgery can alone be fairly tested. I think, nevertheless, that the "settled inerpediency" of the operation remains yet unproved; and leave, therefore, further experience to determine upon the propriety of attempting the saving of the limb by cutting out the joint in certain cases of incurable disease of the knee.

At the hazard of incurring the charge of "recklessly risking life", "unprofitably spending time", and of having taken a step in surgery "in the wrong direction", I publish

- Provincial Medical and Surgical Journal, No. xr, 1850.

Ibid. Ni). II, 1848.
Ibid. No. VuI, 1846. 
the nates and these few crude remarks on a case, the progress and termination of which has afforded here considerable interest and pleasure.

Fing s I Inn, July $26 \mathrm{th}$, 1854.

P.S. For the accompanying sketch, taken in February last, I am indebted to a late intelligent pupil of mine, Mr. Donald MacPherson, of King's College, London. It is due also to our excellent house-surgeon, Mr. Coulcher, to add my acknowledgement of his skilful and diligent attention to the case.

\section{CASES OF UTERINE HAMORRHAGE : WITH REMARKS.}

By T. L. WALFORD, Esq.

[Read before the Pathological Society of Reading, May 10th, 1854.]

CASE I. On the evening of Oct. 31st, 1850, I attended Mrs. G., in labour with her sixth child. Of her history I need only say, that she was weakened, not only by having borne children, but by losses of blood in previous labours, by severe illnesses, and invariably prolonged lactation.

The child was born without any difficulty; and, immediately after the tying of the cord, the hand was applied over the uterus, which still felt large, and by firm friction, it was attempted to excite it to a vigorous contraction. It did contract; and the bandage being carefully tightened, I proceeded to remove the placenta. In this, however, I was not successful, as it was still within the uterus. I then undid the bandage, and by friction, grasping the body of the uterus, again endeavoured to excite such a contraction as would separate and expel the placenta into the vagina. Some blood was escaping during this time, and at last the patient became faint. Finding these ordinary means of no avail, the uterus being still large and flabby, faintness existing, and she having no blood to spare, I determined on removing the placenta by introducing $m y$ hand into the uterus. This I effected without any difficulty; and when friction of the uterus was used again, it contracted, and all went on well. I need not detail any further particulars of this case. The inference I draw from it is, that sometimes it is necessary to unload the uterus, to enable it to obey those means which are ordinarily used to excite it to contract normally.

CasE II. The second case is one likewise of hæmorrhage after the birth of the child, but after the expulsion of the placenta. On the morning of July 10th, 1853, I was sent for to Mrs. W., between seven and eight o'clock. Labour commenced at a quarter to seven A.M, with the discharge of the liquor amnii. On my arrival, I found the os uteri well dilated, the pains frequent but ineffectual. This was her fifth confinement, and nothing untoward had ever occurred. Of her physical formation and constitution, it may suffice to remark that she was short, stout, and spongy. As she made no progress, and as she was very large, I thought the easiest way to release her was to introduce the forceps, and bring through the head. At a quarter past ten, therefore, I did so, and in a minute had the head. Some effort was necessary to bring the shoulders through, and the child was born comfortably. On being put into the scales, it weighed eleven pounds. The placenta followed soon, the womb was apparently well contracted, and the bandage carefully applied. Whilst washing my hands, I looked at her and an her rather pale; immediately I undid the bandage, grasped the uterus, used powerful friction, and felt that it contracted. I re-adjusted the bandage, removed the saturated napkins and put others, gave her a dose of secale, and watched. In a few minutes I saw the paleness increase: she began to yawn. I looked at the napkins and saw the blood running from the vagina, like water in a gutter. At once I again grasped the uterus, and a second time felt it contract, as I thought, firmly, normally; I held it so for a short time, re-applied the bandage, and desired the husband to go and see if he could get Mr. Harrinson's asaistance; for upon such occssions two heads are better than one, and the interest of the patient, her husband, and perhaps her children, demand a combination of heads to avert a threatened catastrophe.

Whilst the husband was gone for Mr. Harrinson, I found Whe patient becoming more faint, yawning more frequently, and blood continuing to flow. Without any further delay, I introduced my hand, not for the purpose of unloading the uterus, as in the preceding case, but with the idea that closer contact of the hand with the nerres of the part might do that which external friction had failed in doing, i. e. might excite a full reflex action. When my fingers reached the os uteri (the ragina was filled with clots, which of course escaped), I found it sufficiently rigid not to think of forcing an entrance. With the right hand on the abdomen, and the fingers of the left against as much of the posterior surface of the uterus as I could with the right hand press down before the left, I, instinctively (for I know not how better to describe an unpremeditated act, albeit it displayed one of the characteristics of an act of the reason, viz., that of adaptation to emergencies), compressed the uterus between the right hand and the fingers of the left at its posterior surface, and so held it, until I had the satisfaction of seeing my patient look better, spcak stronger, and cease to yawn. By the time Mr. Harrinson arrived, the emergency had fortunately passed away. He kindly aided me in bandaging with a compress, and in half an hour we left the patient without anxiety. She continued to do well.

REMARKs. The inference I draw from this case is, that when ordinary extcrnal pressure and friction fail to secure whe a normal contraction of the uterus, we should not hesitate to Compress it bering the state of the parts, it will be found that there Considering the state of the parts, it will be found wa behind the utcrus, and then, with the right on the abdomen, it can be brought well between the two. For the reasonableness of doing so, I think it needs only to be remembered, that the normal contraction of the whole organ depends upon the individual contraction of every muscular fibre of which the uterus consists. We expect friction and pressure to excite them to contract; but how imperfectly do we apply, anteriorly, through the abdominal parietes, friction and anteriorly, the posterior surface of the uterus. Again, is pressure to the necessity of applying pressure to the entire, or, as much of the body of the uterus as can be recognised in the direction given by Dr. Waller, p. 113, viz., "grasping the fundus uteri through the abdominal parietes, "grasping the fundus uteri through the abdo double it upon itself?" The idea I think is there. Again, that which appears to me to be wanting in the treatment of this form of hæmorrhage, is a fixed point against which to compress the organ, and so help every fibre to feel and obey the stimulus of pressure ; for, be it remembered, when friction fails, pressure is resorted to. Now, in the mode which I fails, pressure is res I conceive this fixed point is found. And if we will not have this, we can get no other; for, whilst the uterus is high enough to be pressed against the lumbar vertebræ, it is insufficiently contracted; and when we have tebræ, it is insufric a fixed point up to a certain degree of made those vertebræ a fixed point up the uterus is in the circle of the brim of the pelvis, and here I do not know circlc of the brim to get it, at any rate such an one as the watient can bear. So that, on a consideration of the details patient can bear. of pressure as a means of arresting hamorrhage, and an effectual mode in which it can be applied. And so convinced was I, when I had the uterus of the patient between my two hands, of the certain efficiency of the power to arrest two hands, of the certach I was armed, that $I$ then felt, and do now feel, better fortified than ever to cope with the alarming spectacle of flooding.

I can readily anticipate one objection to the principle I have been illustrating: Granted that a normal contraction of the uterus is secured, what proof do you give that it will continue? I reply, the uterus in the case I have narrated 